\title{
Logistics Network Configuration for Seasonal Perishable Food Supply Chains
}

\author{
Javier Arturo Orjuela-Castro ${ }^{1}$ (D), Juan Pablo Orejuela-Cabrera ${ }^{2}$ (D), Wilson Adarme-Jaimes ${ }^{3}$ \\ ${ }^{1}$ Universidad Distrital Francisco José de Caldas (Colombia) \\ ${ }^{2}$ Universidad del Valle, School of Industrial Engineering (Colombia) \\ ${ }^{3}$ Universidad Nacional de Colombia, Engineering Faculty (Colombia) \\ jorjuela@udistrital.edu.co,juan.orejuela@correounivalle.edu.co,wadarmej@unal.edu.co
}

Received: March 2020

Accepted: December 2020

\begin{abstract}
:
Purpose: The logistics network design (LND) lead to different supply, storage and distribution process and result in the flows, these logistics operations have an impact on the performance of the chain of fresh agricultural products. Specifically, in the perishable food supply chain (PFSC) with seasonality, a temporary imbalance between supply and demand is generated, which affects the balance in the flows and affects the losses, costs and response capacity. The location of stakeholders, production, transformation, commercialization and distribution facilities generate the configuration of the PFSC. Likewise, seasonality affects flows and decisions made by actors, which would generate the need to change the configuration of the PFSC. This research proposes a multi-objective, multi-product, multi-echelon for LND model in seasonal PFSC from a developing country with a topography of mountain ranges, where trucks don't refrigerated and inadequate packaging used allow the food to be affected by the variations in altitude, changes in temperature (T0) and relative humidity $(\mathrm{RH})$. The model was evaluated through a case study in fresh fruits.
\end{abstract}

Design/methodology/approach: Tow mixed linear programming (MILP) multi-objective sub-models are established that determines the multiple configurations of the logistics network of the PFSC with seasonally and allows stakeholders to approach efficiency frontiers, which contribute to their permanence in the markets. The model was applied to the case of the perishable fruit supply chain, in a developing country, Colombia. The population information was taken from government surveys and studies, which allowed parameterizing the model.

Findings: The application of model permitted to answer the next questions: How does improve the performance from seasonal PFSC through logistics network design? And, How the existence of smallholdings in food production and from retail merchants is preserved? It is necessary, on this context of the seasonal perishable food supply chain, to propose a model that changes its objectives in times of oversupply or shortage. Specifically, on a developing country with a topography of mountain ranges, where don't used refrigerated trucks nor adequate packaging.

Social implications: Due the perishable food supply chain stakeholders are located in non-efficient borders and their permanence in the markers may be affected by competition, must be guaranteed the existence of smallholdings farmers and small retail merchants avoiding monopolies. What contributes on increasing food availability and improve access and therefore food security. the stakeholders should focus on increasing food availability and reducing losses to improve access and therefore food security. 
Originality/value: Due the seasonality of agricultural products tht generates an imbalance between supply and demand, a new methodology for the change logistics network configurations of seasonal perishable fruit supply chain was development, the optimizing from five objectives with two multi-objective sub-models is obtained. One for surplus and the other for de deficit moments. The methodology includes real conditions, such as, fruit loss due T0 and RH by different thermal floors, packing and the means transport not refrigerated used, in mountain areas at countries in route of development. The impact over the small producers, retailers and consumers in the times of scarcity or surplus was analyzed.

Keywords: optimal multi-objective model, seasonal fruit perishable, security food; food supply chain

\section{To cite this article:}

Orjuela-Castro, J.A., Orejuela-Cabrera, J.P., \& Adarme-Jaimes, W (2021). Logistics network configuration for seasonal perishable food supply chains. Journal of Industrial Engineering and Management, 14(2), 135-151. https://doi.org/10.3926/jiem.3161

\section{Introduction}

The location of the stakeholders and the production, transformation, commercialization and distribution facilities generate the supply Chain (SC) configuration. Due to the importance of geographic dispersion, the intensity and frequency of the flows between these facilities, modeling techniques such as optimization have been applied to achieve better performance measures in the PFSC. Logistic flows in the PFSC are influenced by the LND, which affects losses and food security. The food supply chain (FSC) studies are recent, with few logistics articles on perishable foods (Orjuela Castro \& Jaimes, 2017).

The duration and conditions of logistics operations have a significant impact on the performance of a logistics network for fresh agricultural products. Logistics network designs (LND) lead to different conditions of supply, storage and distribution (Orjuela-Castro \& Adarme-Jaimes, 2018). When making decisions on LND, the consequences of delivery time and quality must be taken into account as food deterioration is not uniform and generates heterogeneity in its degradation (de Keizer, Akkerman, Grunow, Bloemhof, Haijema \& van der Vorst, 2017).

Some papers for the food LND are presented below. Gong, Li, Liu, Yue and Fu (2007) resolved inventory and location problem as developing a distribution network design, minimized the total inventory cost of fresh food and wastes in the SC. Tsao (2013) a fresh produce supply network model is designed to determine the optimal the replenishment cycle from marketing corporations, they integrated facility location, inventory allocation. Boudahri, Aggoune-Mtalaa, Bennekrouf and Sari (2013) redesigned of a real agri-food SC for poultry products, they optimized the distribution with a clustering-based location-routing model is applied. Govindan, Jafarian, Khodaverdi and Devika (2014) propose a multi-objective optimization model in a PFSC network, it introduce a two-echelon location-routing problem with time-windows, integrating economic and environment objective. De Keizer et al. (2017) showed as heterogeneous product quality decay should be taken, through a network design model in the horticultural sector. Musavi and Bozorgi-Amiri (2017) presents a SC sustainable location-VRP multiobjective model, the perishability in the distribution and total CO2 emission network is considered. Aljohani and Thompson (2018) studied the impacts of the market re-location on the freight activities for fruit and vegetable retailers that source fresh produce directly from the wholesale market. Hsiao, Chen, Lu and Chin (2018) and Orjuela Castro, Orejuela and Adarme Jaimes (2019) formulated last-mile distribution plan problems with analysis the quality of fruits and vegetables, vehicle routing problems with time windows (VRPTW). Yakavenka, Mallidis, Vlachos, Iakovou and Eleni (2019) develop and employ a multi-objective perishable food LND sustainable model, the model incorporates trade-offs between three aspects of sustainability (cost, lead time and emission). The LND 
in the PFSC presents challenges, given the problems they face in the complex real systems (Novaes, Lima, De Carvalho \& Bez, 2015), the multiplicity of decisions, scales, levels, periods, objectives and the interested parties (Miranda-Ackerman, Azzaro-Pantel \& Aguilar-Lasserre, 2017).

Consumers of fresh foods such as fruits and vegetables demand better properties and greater variety. The short shelf life of food makes management difficult their and perishable nature makes its logistics (Aramyan, Ondersteijn, Van Kooten \& Oude Lansink, 2006). In the PFSC there is a continuous change in the quality of the product from the moment it leaves the cultivator until it reaches the consumer, which generates losses. It is estimated that one third of world food production is wasted or damaged (Gustavsson, Cederberg \& Sonesson, 2011), in developing countries post-harvest losses often exceed 50\% (WFPC LLC, 2014). De Keizer, Haijema, Bloemhof \& Van Der Vorst, 2015) design a logistics network for distributing perishable products was used, they showed that if quality decay is not taken into, which results in not meeting service levels and excess waste. The models do not incorporate the inherent characteristics food (Manzini \& Accorsi, 2013), such as shelf life, organoleptic attributes or freshness and innocuity or the incidence of the cold chain (Soto Silva, González Araya, Oliva Fernández \& Plà Aragonés, 2017).

There is a need to include temperature behavior in the shelf life of the food, as well as in transport and inventory. Cold chain as a temperature-controlled supply chain has emerged to ensure the quality food, Sun, Wu and Chen (2018) proposed a method to optimize a logistics cold chain for distribution center for a Factory. However, implementing cold chains for perishable foods in developing countries has difficulties as shown on Gligor, Tan and Nguyen (2018). While the Shashi, Cerchione, Singh, Centobelli and Shabani (2018) study showed the importance of the cold chain in perishable foods, on developing countries, fresh foods are not transported with cold chain (Orjuela-Castro \& Adarme-Jaimes, 2018), due to the difficulty of implementing (Gligor et al., 2018).

Food security (FS) includes sufficient and stable availability of food, timely and permanent access to them in quantity, quality and safety (CISAN-ICBF, 2013; IICA-PRODAR, 2009). The balance between logistic flows could affect the FS, given its effect on availability and access (Orjuela Castro \& Jaimes, 2017; Orjuela Castro, Aranda Pinilla \& Moreno Mantilla, 2019). When the offer exceeds the demand, a management focused on costs will generate that the closest producers and with the highest volume are those considered in the network, therefore a vision of food sustainability must guarantee a significant number of players and minimize oligopolies or monopolies (Farahani, Rezapour, Drezner \& Fallah, 2014), the exclusion of farmers should be avoided and a balance with low costs. On the other hand, when there is deficit, the strongest actors in the chain will concentrate the available food, restricting its access, since it would only be available to their interested, in this sense it is necessary, the existence of a large number of retail merchants for to reduces food security risk (Accorsi, Baruffaldi, Manzini \& Tufano, 2018). Likewise, it is important to guarantee a timely supply, which implies a short supply time.

It is found that the models leave out key stakeholders such as processors, supermarkets and retailers (Utomo, Onggo \& Eldridge, 2018). Different studies on the PFSC propose improvements to farmer supply and urban demand. Researchers have studied how to make logistics of producers more efficient the with cluster formation (Bosona \& Gebresenbet, 2011). Regarding demand, the authors study competitive vs. collaborative markets in FSC retailers. Accorsi et al. (2018) improve logistics performance by forming demand clusters. Mainly, research papers are found in developed countries, future research in developing countries should focus on reducing losses and increasing food availability (Lemma, Kitaw \& Gatew, 2014).

One the biggest problem in the PFSC there is an imbalance between supply and demand, with periods of high and low supply being generated, while the demand does not respond in the same way, which affects the balance in the flows (Orjuela Castro, Diaz \& Bernal, 2017). Specifically, in supply chains with seasonal fruits, this imbalance is common, which forces the reconfiguration of the chain, this affects different strategic decisions such as selection of suppliers, location of facilities, among others (Nayeri, Paydar, Asadi-Gangraj \& Emami, 2020), however, to ensure that the reconfiguration of the chain is sustainable, it is required to meet multiple objectives at the same time (Niu, Tan, Liu, Liu, Yi \& Wang, 2019). Many times, these objectives are in conflict and compete for limited resources, which complicates the problem (Trisna, Marimin, Arkeman \& Sunarti, 2016). 
Studies show the concern of producers by finding themselves in borders far from efficiency (Orjuela-Castro, Batero-Manso \& Orejuela, 2018), and the interest of retailers to improve their performance responding to the different cultures of consumers, further the availability and access are affected by competition stakeholders.

The questions arises: How is the existence of small farms in upstream food production in the FCS (Clark \& Inwood, 2016) and downstream retailers preserved? This would distribute the power of the market (Accorsi et al., 2018). How should a logistics network in the PFSC be configured and reconfigured in an environment of seasonality in which there are periods of over-supply and others of deficit?. What performance measures should be considered in each period that permit sustainability and food security?. How do the geographical conditions and the logistics operations culture on PFSC in developing countries affect to the modeling of the LND problem?

The article is organized in five parts, on the second the methodology is showed, the case of study is presented in the third part, then the results and their analysis. Finally, fifth part, the conclusion and future works is showed.

\section{Methodological Design}

\subsection{Model for the PFSC Logistics Network Design}

Two MILP multi-echelon, multi-objective, multi-product sub-models are established that allows to determine the configuration of the seasonal PFSC Logistics Network and to approach the efficiency frontiers for performance measures, response capacity, quality and efficiency, which contributes to the permanence of the PFSC stakeholders in the markets in developing countries.

\subsubsection{Location for Facilities in the PFSC}

The Multi-objective mathematical model proposed for SC perishable fruits (SCPF) was based on the model proposed by Orjuela-Castro, Sanabria-Coronado and Peralta-Lozano (2017), which include different thermal floors and their impact on the perishability of different types of fruit. Perishability is calculated on the basis of three aspects: i) the loss of fruit due to the manipulation in the storage nodes, ii) due to climatic iii) change of temperature $\left(\mathrm{T}^{\circ}\right)$ and relative humidity $(\mathrm{RH})$, derived from different thermal floors. In this investigation the excess inventory in the different nodes is considered, which forces to dispatch all the production of the farms or to incur a penalty for it. The model establishes the location of the collection centers and distribution (wholesalers), considers as offering nodes each municipality of producers and as plaintiff's nodes of transformation, market places, hypermarkets and shopkeepers, Figure 1.

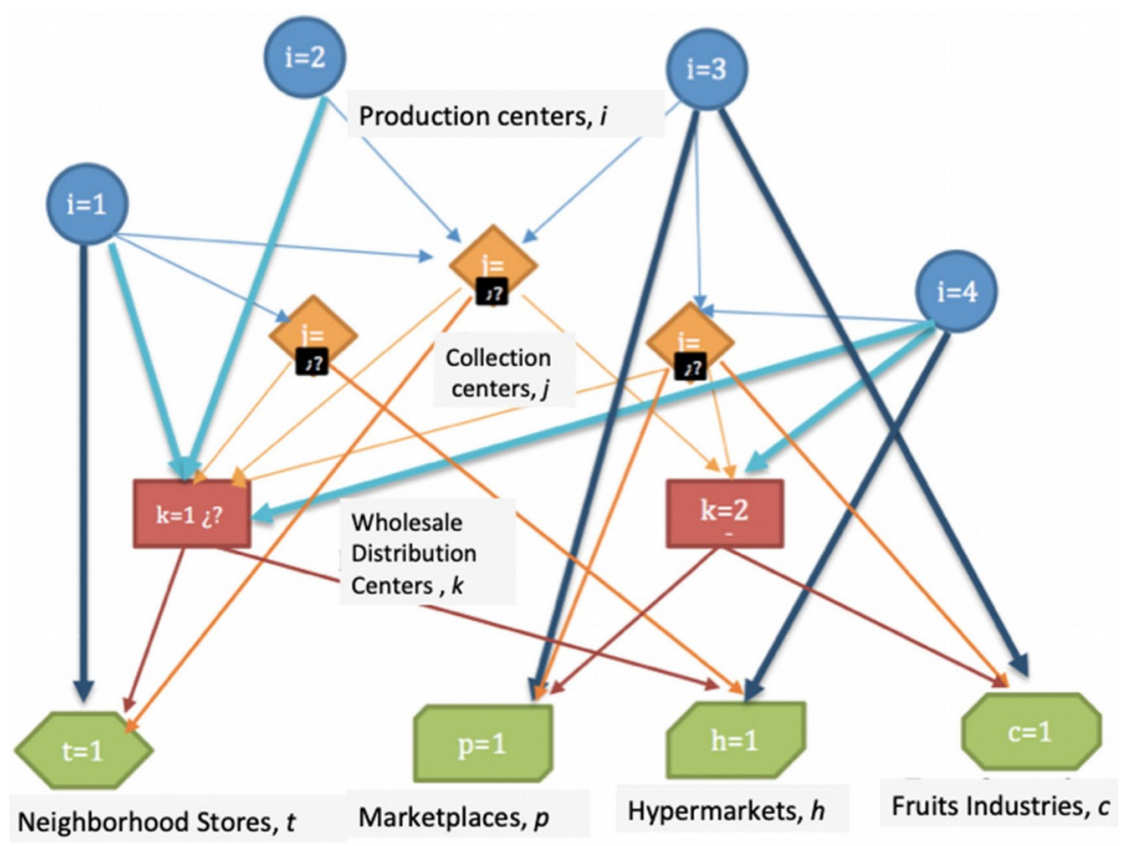

Figure 1. Graph Location Model 
The general model optimizes based on five objectives. The formulation includes the definition of the sets, parameters, decision variables, the objective functions, the constraints (flow balance, capacity and demand) and the types of variables (see the appendix). The fundamental components of the formulation of the two sub-models, the oversupply and the deficit, are presented below.

\subsubsection{General Objective Function}

The five objective functions minimize the costs of transport, service time and the loss of perishable food due to change of temperature $\left(\mathrm{T}^{\circ}\right)$ and relative humidity $(\mathrm{RH})$ and storage in warehouses, the other two objectives maximize the number of clients served and number of producers. The decisions are about opening of collection and wholesale centers, transport and the presence of excesses or shortages of different warehouses, the flows also are determined.

\subsubsection{Variables and Constraints}

The variables are the opening of collection $X_{j}$ or distribution centers $Y_{k}$, as well as the allocation of flow $\mathrm{WN}_{\text {fod }}$ and excess SFI. The constraints are those of flow balance for supply, demand and distribution in all echelons, those of capacity control for collection and distribution centers.

The set of constraints guarantees the flow balance for each agricultural zone $\mathrm{i}$, for each perishable food $\mathrm{f}$ available, requires that the offer that each production zone $i$ has for each available $\mathrm{f}$ food be sent to all destination nodes $\mathrm{d}$, or stay in the production area (ZP). The flow balance is also guaranteed in each wholesale collection unit (CC) or wholesale (WD) $\mathrm{k}$, for each food $\mathrm{f}$ that it can receive. For this, it is required that the amount of each perishable food (AP) that arrives from all areas of production (ZP) and of all the CCs, is equal to the amount that leaves from that type of AP towards all possible destinations of the CC/WD plus the excess of AP remaining in the CA/WD, taking into account the losses. The balance considers losses due to changes in $\mathrm{T}^{\circ}$ and $\mathrm{RH}$ between the flows of the ZP-CC, ZP-WD and CC-WD due to storage.

The capacity constraints guarantee the flow relationship, between what leaves from the CC/WD and the decision to open the CC $\mathrm{j}$ or WD $\mathrm{k}$. It means that if it is not open, no flow is sent from it, if the CC/WD is opened, it forces the flows to be greater than the minimum required opening capacity, and less than the maximum capacity of the CC or WD.

For each of the final customers (FC): Stores (t), Squares (p), Hypermarkets (h) and Transformers or industries (c), proportions of total demand are presented, which generates orders from suppliers: ZP, CC and /or WD. In this sense, there are constraints that guarantee that the demand is met. This requires that everything sent from ZP, CC and /or WD to each final customer (FC) is equal to what is demanded plus excess AP in the FC. Likewise, the balance considers the losses due to changes in $\mathrm{T}^{\circ}$ and $\mathrm{RH}$ in the flows between nodes and storage.

\subsubsection{Seasonality Implications and Sub-Models}

For the evaluation of the performance of the PFSC, a series of metrics have been proposed, which can be classified into indicators of efficiency, response capacity and flexibility (Bigliardi \& Bottani, 2010), in the FPSA there is a need to include quality, shelf life, product safety (Aramyan et al., 2006), access, availability, logistics performance and losses (Orjuela-Castro \& Adarme-Jaimes, 2018).

In accordance with the literature review and the Perishable Fruit Supply chain (PFrSC) behavior at the region of the study, five performance metrics were selected. Therefore, there would be five objectives, which exceeds the recommended number in multi-objective optimization and an amount that cannot be represented in a three-dimensional scheme (Govindan et al., 2014).

The PFrSC that present seasonality in the supply generate a relationship between supply-demand with periods of surplus or deficit. With the purpose of modeling that imbalance between supply-demand due to the seasonality in PFrSC, the problem has been divided into two sub-models, one for the moment of oversupply and the other for periods of shortage. For the first case of oversupply, three objective functions are proposed: the reduction of losses, the variable cost of transportation and maximizing the number of producers involved. On the other hand, the scenario with scarcity requires including two objectives: to maximize the number of clients served and to minimize the attention time (Lead-time). Below are the two sub-models. 
Figure 2 shows the decision algorithm used when seasonality in the supply is present. if there is an oversupply, the surplus model is applied. In the opposite case, supply shortages, the deficit model is applied. Being a multi-objective model, the pareto frontier is found and then the solution is selected. When the season changes, the algorithm is repeated again.

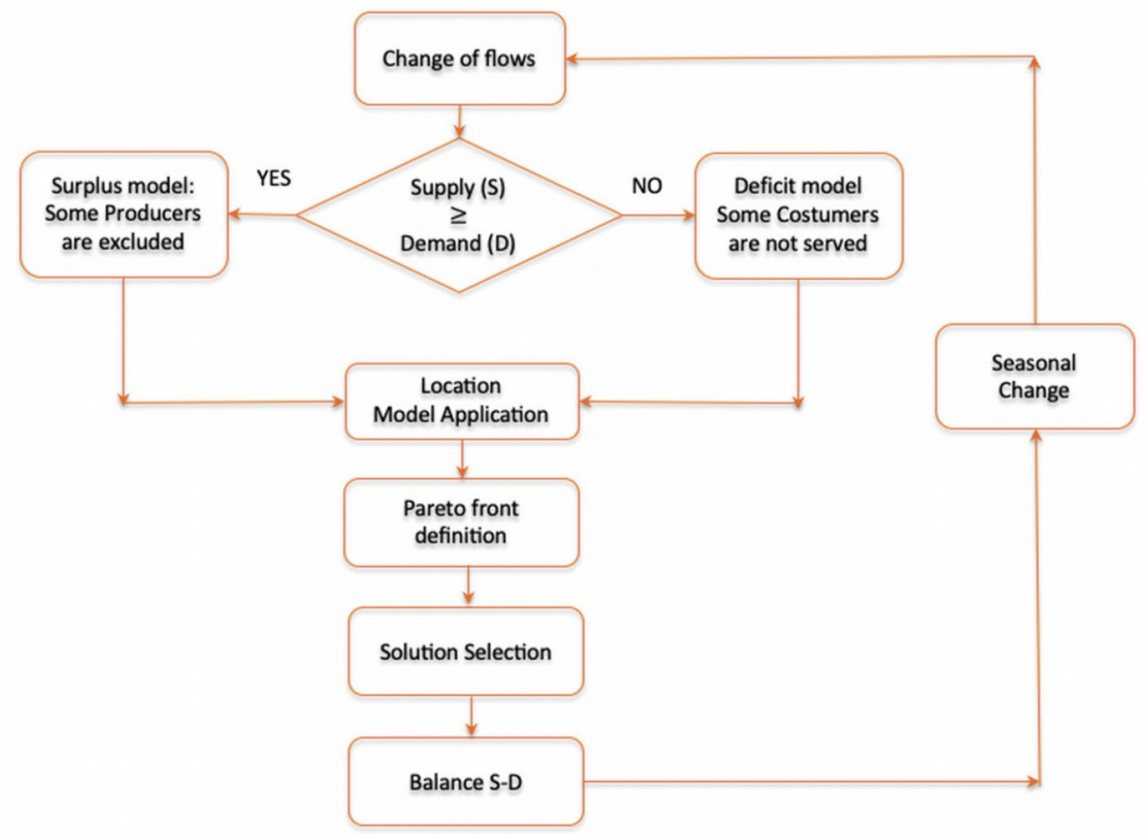

Figure 2. Decisions for the Configuration of the PFSC

\subsection{Surplus Model}

For this model, the following objective functions are established.

\subsubsection{Objective Function}

$$
\text { Minimize } \mathrm{Z}=\mathrm{F}(\mathrm{OBJ} 1, \mathrm{OB} 2,-\mathrm{OBJ} 3)
$$

\subsubsection{Minimization of Losses}

$$
O B J 1=M I N Z 1=\sum_{o \in T} \sum_{d \in D T} \sum_{f \in(F O T\{o\} \cap F D T\{d\})} W N_{f o d} *\left(T n_{o d}+H N_{o d}\right)
$$

This function seeks to reduce losses that depend on intermediate nodes, logistics and transport processes, preserve organoleptic, biophysical characteristics and generate availability and consumer satisfaction when the demand is met. In the consolidation centers the characteristics of packaging and conservation are improved by reducing losses, therefore the passage through these Hubs is favored. If the offer is less than the demand, there are only losses in the warehouses of final consumers.

\subsubsection{Minimization of Transport Cost}

$$
O B J 2=M I N Z 2=\sum_{o \in O T} \sum_{d \in D T} \sum_{f \in(F O T\{0\} \cap F D T\{d\})} C T_{o d} * D I N_{o d} * W N_{f o d}
$$

The cost of transport grows by adding intermediate nodes since the distances traveled increase, therefore the decrease of them is sought. In developing countries, small vehicles are used in the first and last mile, which makes it 
difficult to find benefits by transport scale. The only cases in which these economies of scale occur are between collections centers (CCs) and warehouse distributions (WDs). This performance measure punishes the opening of the CCs or WDs, favors direct travel, and presents a positive relationship with the time of transport, dispatch, supply and the level and cost of inventory.

\subsubsection{Maximize Number of Suppliers}

$$
O B J 3=M A X Z 3=\sum_{i \in I} B P I_{i}
$$

With the purpose of contributing to the permanence of smalls producers in the market, in times of oversupply, a model without this objective function excludes producers that, for reasons of distance, generate high transport costs, while by including it actively all producers with a minimum load, could to be generate excesses in the nodes or specialize the type of fruit to be sent from the supplier.

A new variable (BPI) appears that considers whether the farmer is included i, this implies the appearance of new constraints: a redundant so that a producer that is not activated is zero, of opening and minimum flow from the producer.

\subsection{Deficit Model}

Applies for moments of scarcity.

\subsubsection{Objective Functions}

$$
\text { Minimize Z= F (OBJ1, OB2, }- \text { OBJ3) }
$$

The first objective loss function does not change from the previous sub-model.

\subsubsection{Minimization of the Estimated Average Service time}

For each of the final customers $\mathrm{d} 2 \in \mathrm{DF}$, the tim

e is given by the weighted average of the service time each of the three echelons has: producers, CC and WD.

$$
O B J 4=M I N Z 4=\sum_{d 2 \in D F} L T D 2 E_{d 2} * \frac{D N T_{d 2}}{\sum_{d 2 \in D F} D N T_{d 2}}
$$

\subsubsection{Maximize the Number of Clients Served in the Process}

In times of deficit, a model without this objective function excludes retail customers; with it activates retail customers with minimal supply.

$$
O B J 5=M A X Z 5=\sum_{d 2 \in D F} B P D 2_{d 2}
$$

For the particular formulation of the supply deficit model, it was necessary to add the minimum demand parameter, the binary variable of appearance of a customer (retained retailer) and the redundant constraints, of control with minimum flow and the relations of flow and opening, of demand minimum and maximum for each echelon.

\subsection{Pareto Front}

In multi-objective optimization, each solution has an $\mathrm{n}$-tuple, where $\mathrm{n}$ is the number of objectives. From all the solutions, the non-dominated ones must be found, fulfilling the condition that there is no other point that is better than or equal in all the objectives and strictly better in any of the objectives. The set of all non-dominated solutions forms the Pareto frontier. To find a set of solutions (Schulz, Neufeld \& Buscher, 2019), then the Pareto frontier was found applying the dominance algorithm proposed by (Deb, Pratab, Agarwal \& Meyarivan, 2002). 


\subsection{Solution selection}

As a result of multi-objective optimization, the Pareto frontier is obtained, this represents the set of efficient solutions against the objectives, however in practical terms, for decision makers choosing the solution to implement is a challenge (Wang, Shi, Hu, You, Bai \& Guo, 2020). In order to address this difficulty, in this investigation the solution of the Pareto frontier that has the smallest sum of the normalized distance between its objectives and the medians of the objectives on the frontier points are selected, which allows selecting an efficient point with the greatest balance between objectives.

\section{Case Studies. The SCPF Cundinamarca-Bogotá, Colombia}

The country Colombia has 32 departments, Cundinamarca is the third most populous with 2,800,000 inhabitants without Bogota, capital of Colombia. Cundinamarca has $22,623 \mathrm{~km}^{2}$, located in the eastern mountain range, with a diversity of thermal floors, produces of a variety of foods. It supplies more than $60 \%$ of the food consumed by Bogotá, the most populous city with 7,674,366 inhabitants by 2018 on $1,775 \mathrm{~km}^{2}$.

In this context, the two sub-models were applied to five SC of perishable fruits (PFrSC), this given the consumption in Bogota and the production of Cundinamarca. Based on the application of the characterization methodology (Orjuela Castro, Díaz et al., 2017), the behavior of the PFrSCs was established. The units of analysis were the stakeholders of the SC. The fruits selected were, two fruits of cold climate, blackberry and strawberries. Three of warm climate, Mango, Tangerine and Orange.

\subsection{Survey of Information}

The gathering of information allowed establishing the behavior of market competition and flows. The field data was obtained from surveys applied to the PFrSC stakeholders in two periods, between 2014-2015 (GICALyT group from Universidad Distrital) and between 2016-2017 (SEPRO group from Universidad Nacional). The primary information was supplemented with secondary information through documents of the Ministry of Agriculture 2006-2016 for the Agronet offer, for demand, studies from the Secretariat of Development of Bogotá 2006-2009 and the ENSIN survey 2005, 2010 and 2015. The above was complemented with data from FAO, WTO and TRADE-MAP. Six possible municipalities of Cundinamarca were taken for location of CCs, as WDs four possible locations in the extremes of Bogotá. On the other hand, 24 municipalities and as customers 5 market places, 5 large hypermarkets, 2 agribusinesses, 12 locations (where retailers are located).

Through non-probabilistic sampling, 109 surveys were applied to producers, 65 to transporters, 3 to agribusiness, 3 to large hypermarkets, 350 to shopkeepers in the neighborhood, 154 to merchants in market places and 79 to wholesalers in Corabastos, the largest supply square of Bogotá. The number of questions included was 132 to the different stakeholders, establishing the behavior of 251 parameters. Which allowed establishing the demand of the industry, wholesalers, shopkeepers and market places in Bogotá, the offer from Cundinamarca to Bogotá, the parameters of transport and storage times and costs, fruit losses in the PFrSC, rates of production, per capita consumption and flows between the different links.

\section{Results}

The two Multi-objective sub-models for the two seasons, allowed establishing new configurations of the PFrSC, according to the five performance measures. The purpose was to determine how many facilities and where the CCs (Cundinamarca) and WDs (Bogotá) should be located. Then the allocation and flows between the nodes were determined, the PFrSC is reconfigured and evaluates how it affects the stakeholders, by placing them in performance measures closer to efficient borders.

\subsection{Sub-Models}

For the surplus sub-model, three objectives were evaluated, 250,000 runs were carried out in AMPL to obtain the borders. In the sub-model with supply deficit contemplated three objectives, 260,020 runs were made. The e-constraints method was applied, the total variables were 2401, 33 binaries and 2368 linear, 422 equality constraints and 1514 with inequality. The solutions were obtained through Gurobi 7.5.0. 
Figure 3 shows the results of the objective functions, plotted in Matlab. In (a), the Pareto border obtained by applying the non-dominance technique, proposed by Wilfredo Federico Pareto (1848-1923), is presented for the three objective functions of the surplus sub-model. In (b) the three objective functions of the sub- deficit model, applying e-constraints. In the figure 3, it can be seen that the application of the designed sub-models, allowed determining the borders of Pareto, orange, which demonstrates the robustness of the model and the goodness of the applied technique of solution.

To carry out the analysis that allows the best decision making for the stakeholders, the configurations for the two sub-models were made. this means three configurations, where each objective is optimal and another one with the means statistics ones in search of the balance between the three performance measures. Then, the non-dominated point near it was searched for. The CCs and WDs open for each configuration of the two sub-models are presented, Table 1. Initially in part a. the results of the surplus model are presented, then in part b. The results of the model for deficit are shown.

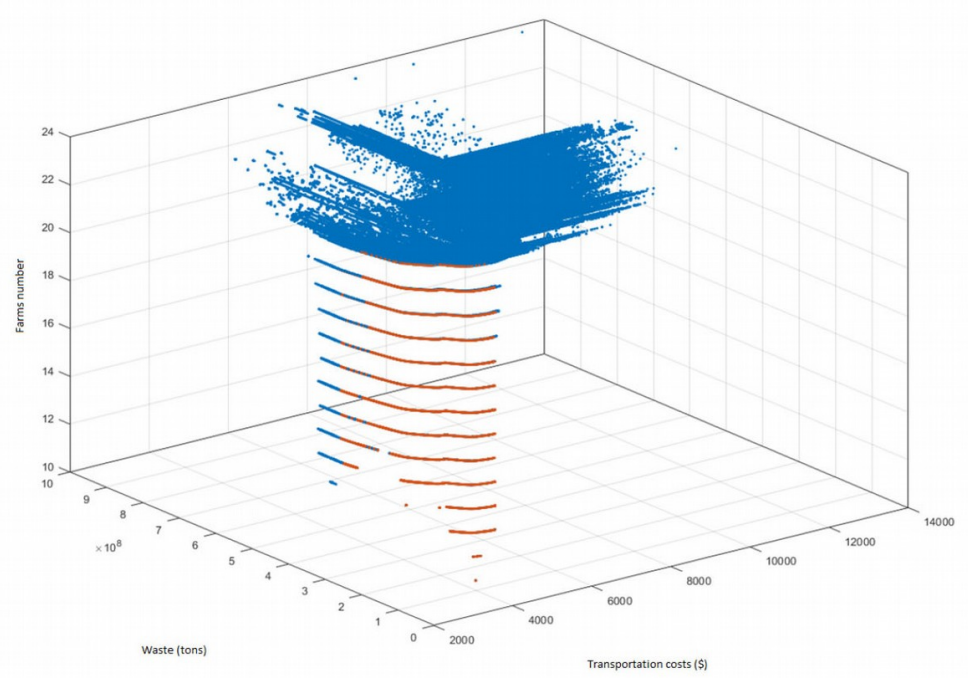

(a) Efficient Pareto Borders (5440) for the surplus sub-model

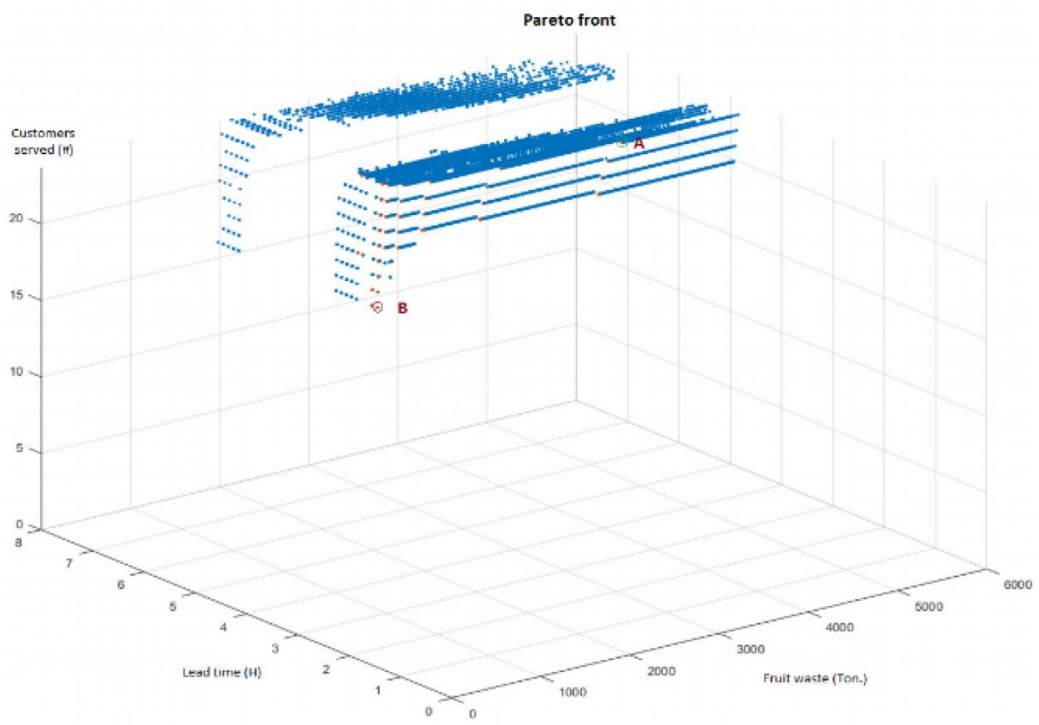

(b) Efficient Pareto Borders (974) for the deficit sub-model

Figure 3. Pareto borders for the two sub-models 


\begin{tabular}{|c|c|c|c|c|c|}
\hline \multicolumn{6}{|c|}{ a. Surplus model } \\
\hline \multirow[b]{2}{*}{ Objective } & Objective Min BJ1 & Objective Min BJ2 & & Objective Max BJ3 & \multirow{4}{*}{$\begin{array}{l}\text { Seeking Balance } \\
\text { Another with the } \\
\text { Median of Obj 1, } \\
\qquad 2 \text { and } 3\end{array}$} \\
\hline & Minimize Losses & $\begin{array}{c}\text { Minimize Transportati } \\
\text { Costs }\end{array}$ & & $\begin{array}{l}\text { Maximize Farmers } \\
\text { suppliers }\end{array}$ & \\
\hline Units & Thousands (\$) & $\begin{array}{c}\text { Ten thousand of } \\
\text { millions }(\$)\end{array}$ & & $\begin{array}{l}\text { Number of } \\
\text { Municipalities }\end{array}$ & \\
\hline Optimum value & 2.16 & & 6.2 & 24 & \\
\hline Location & \multicolumn{5}{|c|}{ Open Collection centers (CC) } \\
\hline Anapoima (25) & 25 & \multicolumn{2}{|c|}{25} & 25 & 25 \\
\hline Cachipay (26) & 26 & \multicolumn{2}{|r|}{26} & 26 & 26 \\
\hline La Mesa (27) & 27 & \multicolumn{2}{|r|}{27} & 27 & 27 \\
\hline Tocaima (28) & $\mathrm{NC}$ & \multicolumn{2}{|c|}{$\mathrm{NC}$} & $\mathrm{NC}$ & $\mathrm{NC}$ \\
\hline San Bernardo (29) & $\mathrm{NC}$ & \multicolumn{2}{|r|}{29} & $\mathrm{NC}$ & 29 \\
\hline Sibate (30) & 30 & \multicolumn{2}{|r|}{30} & 30 & 30 \\
\hline Location & \multicolumn{5}{|c|}{ Open Distribution Centers (WD) } \\
\hline Codabas (31) & $\mathrm{NC}$ & \multicolumn{2}{|c|}{31} & 31 & 31 \\
\hline Ciudad Bolívar (32) & 32 & \multicolumn{2}{|r|}{32} & 32 & 32 \\
\hline Corabastos (33) & 33 & \multicolumn{2}{|r|}{33} & 33 & 33 \\
\hline Paloquemao (34) & $\mathrm{NC}$ & \multicolumn{2}{|r|}{34} & 34 & 34 \\
\hline \multicolumn{6}{|c|}{ b. Deficit Model } \\
\hline \multirow{2}{*}{ Objective } & Objective Min BJ1 & Objective Min BJ4 & & Objective Max BJ5 & \multirow{4}{*}{$\begin{array}{l}\text { Looking for the } \\
\text { Balance Another } \\
\text { with the Median } \\
\text { of Obj } 1,4 \text { and } 5\end{array}$} \\
\hline & Minimize Losses & Minimize Lead Time & Mas & imize Customers Served & \\
\hline Units & Thousands (\$) & Time (LT) & \multicolumn{2}{|c|}{ Number of customers served } & \\
\hline Optimum value & 1.98 & 4.4 & & 12 & \\
\hline Location & & Open Collectic & ion ce & nters (CC) & \\
\hline Anapoima (25) & 25 & $\mathrm{NC}$ & & NC & 25 \\
\hline Cachipay (26) & 26 & $\mathrm{NC}$ & & 26 & 26 \\
\hline La Mesa (27) & 27 & 27 & & $\mathrm{NC}$ & 27 \\
\hline Tocaima (28) & $\mathrm{NC}$ & $\mathrm{NC}$ & & 28 & $\mathrm{NC}$ \\
\hline San Bernardo (29) & $\mathrm{NC}$ & 29 & & 29 & 29 \\
\hline Sibate (30) & 30 & 30 & & 30 & 30 \\
\hline Location & & Open Distributi & ion $\mathrm{C}$ & enters (WD) & \\
\hline Codabas (31) & $\mathrm{NC}$ & $\mathrm{NC}$ & & 31 & 31 \\
\hline Ciudad Bolívar (32) & 32 & $\mathrm{NC}$ & & 32 & 32 \\
\hline Corabastos (33) & 33 & 33 & & $\mathrm{NC}$ & 33 \\
\hline Paloquemao (34) & $\mathrm{NC}$ & $\mathrm{NC}$ & & 34 & 34 \\
\hline
\end{tabular}

NC: Not Chosen

Table 1. Location of Collection Centers (Cundinamarca) and Distribution (Bogotá D.C)

Table 1, shows the different configurations of the logistics network. For objective 1, the same location is obtained for both CCs and WDs in the two sub-models, as well as in the medians of the three objectives. For the surplus sub-model, the same locations of the WDs with objectives 2 and 3 are obtained. When prioritizing the other 
objectives, different locations are obtained, it should be noted that no matter the objective, CCs 30 would always open (in the municipality of Sibate). As an illustration on map 1, the locations with the medians of the objectives are presented.

Figure 4 shows the flows derived from the configurations presented on map 1. It can be seen that although it has the same locations for CCs and WDs, the flows between the echelons are different between the surplus and deficit sub-model.

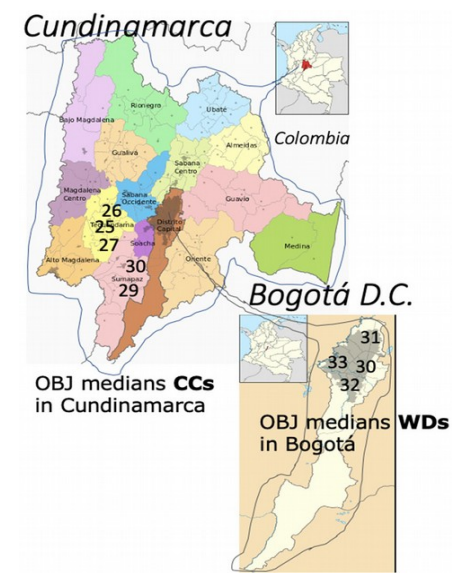

Map 1. Collection Centers (CCs) and Wholesaler Distribution Center (WDs)

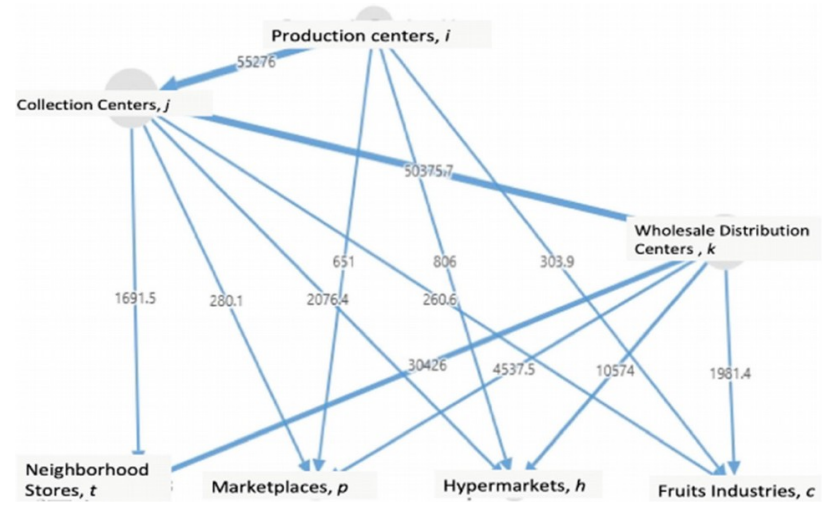

(a) With the medians of the three objectives surplus

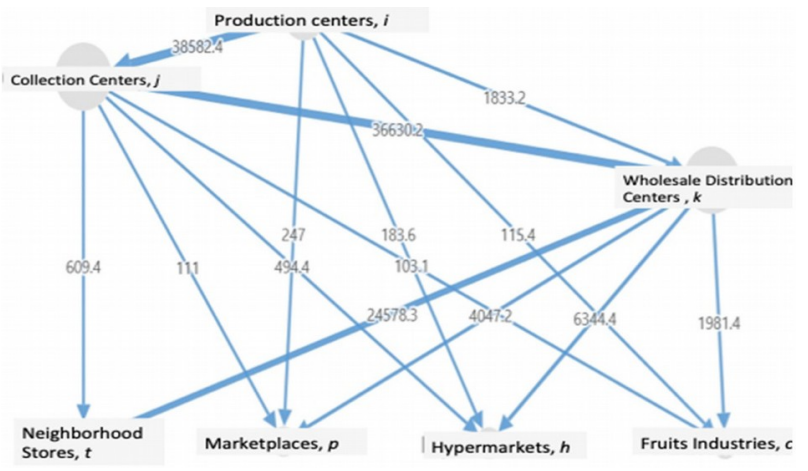

(b) With the medians of the three objectives deficit.

Figure 4. Flows based on objectives, warm climate fruits

\subsection{Discussion of Results}

The configuration establishes the location of CCs facilities in regions of fruit production and WDs in areas of consumption, by applying the two sub-models, one for moments of surplus and another for periods of deficit. The 
multi-objective, multi-product and multi-level optimization models designed, allowed showing different designs of the logistics network and different flows between the echelons. With an appropriate LND and adequate logistic means, transportation and specialized warehouses, losses will be reduced and response capacity will be improved. The existence of intermediate nodes allows the consolidation of orders and food preservation, achieves economies of scale by moving volumes, a fundamental element in the performance of the PFrSC and shows that stakeholders can move to borders that are more efficient. Due to the tradeoff found among the performance measures, in order to decide what the appropriate configuration should be with respect to the five objectives evaluated, government institutions and guilds should gather the different agents of the PFrSC and apply multi-goal models, given various interests of stakeholders.

In times of surplus, the most affected are the producers, due to the low sales prices that do not cover their costs, the most benefited are the consumers as access is increased, in these periods of oversupply the availability will can be jeopardized discouraging the production. In times of scarcity an opposite effect is generated, producers earn with high prices and consumption is discouraged. The two multi-objective optimization models designed exceed what was found in the literature by including on one hand the effects of $\mathrm{T}^{0}$ and $\mathrm{RH}$, recommendation made by van der Vorst, Schouten, Luning and van Kooten (2014).

When contemplating the different thermal floors and the means used for the transport of fruits in mountain areas, geographic region where the case study is applied, in developing countries; the models give a better representation of reality for PFrSC, manifest lack in the studies of Akkerman, Farahani and Grunow (2010), Goetschalckx, Vidal and Dogan (2002), Soto-Silva, Nadal-Roig, González-Araya and Pla-Aragones (2016), Soto Silva et al. (2017). The design of a multi-objective and multi-level model includes all the echelons of the PFrSC from production to consumption, respond to the call of authors such as Manzini and Accorsi (2013), Van der Vorst, Van Kooten and Luning (2011) and Yu and Nagurney (2013) that demand the inclusion of supply, distribution and demand by containing all the echelons of the PFrSC.

There are several studies that show the need to allow the plurality of stakeholders at the ends of the PFSC, in the field of producers (Bosona \& Gebresenbet, 2011), in the field of retailers (Accorsi et al., 2018). This research contributes to these two ways, by developing the two sub-models for oversupply and fruit deficit. On one hand, availability is achieved with the diversity of producers; the offer in developing countries is guarantor of food security. On the other hand, the large number of retailers, shopkeepers in the neighborhood, counteracts the monopolies of large stores and favors access by guaranteeing competition.

\section{Conclusions and Future Work}

Developing countries that are immersed in internal conflicts require government strategies and actions that allow alternatives to overcome the inequalities present among PFSC agents. In this sense, different interests in the stakeholders that derive in tradeoffs arise. The measures of performance sought should lead to the sustainability of the supply chain to way that guarantees food security, which is why five objectives are proposed: efficiency, responsiveness, quality, permanence of farmers (supply) and from small shopkeepers (demand).

Seasonality in some fruits generates problems of oversupply and shortage in different periods of time this unbalances the logistics flows. For this reason, two models were designed, one of surplus and one of deficit. When running the two sub-models, the results derive different configurations with the five objectives and generate different flows between the echelons and different logistics networks design.

The multi-objective, multilevel and multiproduct model, exceeds what is found in the literature and approaches the reality of PFSCs by including logistic operation conditions of countries under development with mountain geography and food security, where changes in $\mathrm{T}^{0}$ (temperature) and $\mathrm{RH}$ (relative humidity) affect the quality of fruits.

It is necessary to evaluate the transition from one model to another, with the smallest impacts. In other words, given the optimal configuration for deficit, how will be reconfiguring the network for moments of surplus? In a planning horizon, given the network is $\mathrm{A}$, how can pass it to B? with the improvement of the established performance measures, so that changes by periods are controlled. Therefore, the diversity of results, generate the 
need to propose the study with a dynamic approach to the design of logistics networks for PFSC that present seasonality. Being a multi-objective model, for decision making by decision makers, this study could be complemented by a multicriteria model.

\section{Declaration of Conflicting Interests}

The authors declared no potential conflicts of interest with respect to the research, authorship, and/or publication of this article.

\section{Funding}

The authors received no financial support for the research, authorship, and/or publication of this article.

\section{References}

Accorsi, R., Baruffaldi, G., Manzini, R., \& Tufano, A. (2018). On the design of cooperative vendors' networks in retail food supply chains: a logistics-driven approach. International Journal of Logistics Research and Applications, 21(1), 35-52. https://doi.org/10.1080/13675567.2017.1354978

Akkerman, R., Farahani, P., \& Grunow, M. (2010). Quality, safety and sustainability in food distribution: A review of quantitative operations management approaches and challenges. OR Spectrum, 32(4).

https://doi.org/10.1007/s00291-010-0223-2

Aljohani, K., \& Thompson, R.G. (2018). The impacts of relocating a logistics facility on last food miles - The case of Melbourne's fruit \& vegetable wholesale market. Case Studies on Transport Policy, 6(2), 279-288.

https://doi.org/10.1016/j.cstp.2018.03.007

Aramyan, L., Ondersteijn, C.J.M., Van Kooten, O., \& Oude Lansink, A. (2006). Performance indicators in agri-food production chains. Quantifying the Agri-Food Supply Chain, 49-66. https://doi.org/10.1007/1-4020-4693-6_5

Bigliardi, B., \& Bottani, E. (2010). Performance measurement in the food supply chain: a balanced scorecard approach. Facilities, 28(5-6), 249-260. https://doi.org/10.1108/02632771011031493

Bosona, T.G., \& Gebresenbet, G. (2011). Cluster building and logistics network integration of local food supply chain. Biosystems Engineering, 108(4), 293-302. https://doi.org/10.1016/j.biosystemseng.2011.01.001

Boudahri, F., Aggoune-Mtalaa, W., Bennekrouf, M., \& Sari, Z. (2013). Application of a Clustering Based Location-Routing Model to a Real Agri-food Supply Chain Redesign. In Thanh Nguyen, N., Trawinski, B., Katarzyniak, R., \& Jo, G.-S. (Eds.), Advanced Methods for Computational Collective Intelligence. Studies in Computational Intelligence (457, 323-331). Springer-Verlag.

CISAN-ICBF (2013). Conpes 113, 2008. Instituto Colombiano de Bienestar Familiar ICBF. http://www.icbf.gov.co/portal/page/portal/PortalICBF/Bienestar/Nutricion/PNSAN

Clark, J.K., \& Inwood, S.M. (2016). Scaling-up regional fruit and vegetable distribution: potential for adaptive change in the food system. Agriculture and Human Values, 33(3), 503-519. https://doi.org/10.1007/s10460-015-9618-7

de Keizer, M., Akkerman, R., Grunow, M., Bloemhof, J.M., Haijema, R., \& van der Vorst, J.G.A.J. (2017). Logistics network design for perishable products with heterogeneous quality decay. European Journal of Operational Research, 262(2), 535-549. https://doi.org/10.1016/j.ejor.2017.03.049

De Keizer, M., Haijema, R., Bloemhof, J.M., \& Van Der Vorst, J.G.A.J. (2015). Hybrid optimization and simulation to design a logistics network for distributing perishable products. Computers and Industrial Engineering, 88, 26-38. https://doi.org/10.1016/j.cie.2015.06.017

Deb, K., Pratab, A., Agarwal, S., \& Meyarivan, T. (2002). A Fast and Elitist Multiobjective Genetic Algorithm: NGSA-II. IEEE Transactions on Evolutionary Computing, 6(2), 182-197. https://doi.org/10.1109/4235.996017 
Farahani, R.Z., Rezapour, S., Drezner, T., \& Fallah, S. (2014). Competitive supply chain network design: An overview of classifications, models, solution techniques and applications. Omega (United Kingdom), 45, 92-118. https://doi.org/10.1016/j.omega.2013.08.006

Gligor, D., Tan, A., \& Nguyen, T.N.T. (2018). The obstacles to cold chain implementation in developing countries: insights from Vietnam. International Journal of Logistics Management, 29(3), 942-958. https://doi.org/10.1108/IJLM-022017-0026

Goetschalckx, M., Vidal, C.J., \& Dogan, K. (2002). Modeling and design of global logistics systems: A review of integrated strategic and tactical models and design algorithms. European Journal of Operational Research, 143(1), 1-18. https://doi.org/10.1016/S0377-2217(02)00142-X

Gong, W., Li, D., Liu, X., Yue, J., \& Fu, Z. (2007). Improved two-grade delayed particle swarm optimisation (TGDPSO) for inventory facility location for perishable food distribution centres in Beijing. New Zealand Journal of Agricultural Research, 50(5), 771-779. https://doi.org/10.1080/00288230709510350

Govindan, K., Jafarian, A., Khodaverdi, R., \& Devika, K. (2014). Two-echelon multiple-vehicle location-routing problem with time windows for optimization of sustainable supply chain network of perishable food. International Journal of Production Economics, 152, 9-28. https://doi.org/10.1016/j.ijpe.2013.12.028

Gustavsson, J., Cederberg, C., \& Sonesson, U.F. (2011). Pérdidas y desPerdicio de alimentos en el mundo. http://www.fao.org/docrep/016/i2697s/i2697s.pdf

Hsiao, Y.H., Chen, M.C., Lu, K.Y., \& Chin, C.L. (2018). Last-mile distribution planning for fruit-and-vegetable cold chains. International Journal of Logistics Management, 29(3), 862-886. https://doi.org/10.1108/IJLM-01-2017-0002

IICA-PRODAR (2009). Gestión de agronegocios en empresas asociativas rurales: Curso de capacitación. Módulo 1: Sistema agroproductivo, cadenas y competitividad.

Lemma, Y., Kitaw, D., \& Gatew, G. (2014). Loss in Perishable Food Supply Chain: An Optimization Approach Literature Review. International Journal of Scientific \& Engineering Research, 5(5), 302-311.

Manzini, R., \& Accorsi, R. (2013). The new conceptual framework for food supply chain assessment. Journal of Food Engineering, 115(2), 251-263. https://doi.org/10.1016/j.jfoodeng.2012.10.026

Miranda-Ackerman, M.A., Azzaro-Pantel, C., \& Aguilar-Lasserre, A.A. (2017). Sustainability assessment of a transportation system under uncertainty: an integrated multicriteria approach. IFAC-PapersOnLine, 50(1), 7481-7486. https://doi.org/10.1016/j.ifacol.2017.08.1064

Musavi, M.M., \& Bozorgi-Amiri, A. (2017). A multi-objective sustainable hub location-scheduling problem for perishable food supply chain. Computers and Industrial Engineering, 113, 766-778. https://doi.org/10.1016/j.cie.2017.07.039

Nayeri, S., Paydar, M.M., Asadi-Gangraj, E., \& Emami, S. (2020). Multi-objective fuzzy robust optimization approach to sustainable closed-loop supply chain network design. Computers and Industrial Engineering, 148(August), 106716. https://doi.org/10.1016/j.cie.2020.106716

Niu, B., Tan, L., Liu, J., Liu, J., Yi, W., \& Wang, H. (2019). Cooperative bacterial foraging optimization method for multi-objective multi-echelon supply chain optimization problem. Swarm and Evolutionary Computation, 49(May 2018), 87-101. https://doi.org/10.1016/j.swevo.2019.05.003

Novaes, A.G.N., Lima, O.F., De Carvalho, C.C., \& Bez, E.T. (2015). Thermal performance of refrigerated vehicles in the distribution of perishable food. Pesquisa Operacional, 35(2), 251-284. https://doi.org/10.1590/01017438.2015.035.02.0251

Orjuela-Castro, J.A., \& Adarme-Jaimes, W. (2018). Evaluating the Supply Chain Design of Fresh Food on Food Security and Logistics. In Communications in Computer and Information Science (915). Springer International Publishing. https://doi.org/10.1007/978-3-030-00350-0 
Orjuela-Castro, J.A., Batero-Manso, D., \& Orejuela, J.P. (2018). Logistics IRP Model for the Supply Chain of Perishable Food. In J. C. Figueroa-García, J. G. Villegas, J. R. Orozco-Arroyave, \& P. A. Maya Duque (Eds.), Applied Computer Sciences in Engineering (40-52). Springer International Publishing.

Orjuela-Castro, J.A., Sanabria-Coronado, L.A., \& Peralta-Lozano, A.M. (2017). Coupling facility location models in the supply chain of perishable fruits. Research in Transportation Business and Management, 24(August), 73-80. https://doi.org/10.1016/j.rtbm.2017.08.002

Orjuela Castro, J.A., Aranda Pinilla, J.A., \& Moreno Mantilla, C.E. (2019). Identifying trade-offs between sustainability dimensions in the supply chain of biodiesel in Colombia. Computers and Electronics in Agriculture, 161(March 2018), 162-169. https://doi.org/10.1016/j.compag.2018.03.009

Orjuela Castro, J.A., Diaz, G.G.L., \& Bernal, C.M.P. (2017). Model for Logistics Capacity in the Perishable Food Supply Chain. Communications in Computer and Information Science, 742, III-IV. https://doi.org/10.1007/978-3-31966963-2

Orjuela Castro, J.A., \& Jaimes, W.A. (2017). Dynamic impact of the structure of the supply chain of perishable foods on logistics performance and food security. Journal of Industrial Engineering and Management, 10 (4 Special Issue), 687-710. https://doi.org/10.3926/jiem.2147

Orjuela Castro, J. A., Orejuela, J. P., \& Adarme Jaimes, W. (2019). Last mile logistics in mega-cities for perishable fruits. Journal of Industrial Engineering and Management, 12(2), 318. https://doi.org/10.3926/jiem.2770

Schulz, S., Neufeld, J.S., \& Buscher, U. (2019). A multi-objective iterated local search algorithm for comprehensive energy-aware hybrid flow shop scheduling. Journal of Cleaner Production, 224, 421-434.

https://doi.org/10.1016/j.jclepro.2019.03.155

Shashi, S., Cerchione, R., Singh, R., Centobelli, P., \& Shabani, A. (2018). Food cold chain management: From a structured literature review to a conceptual framework and research agenda. International Journal of Logistics Management, 29(3), 792-821. https://doi.org/10.1108/IJLM-01-2017-0007

Soto-Silva, W.E., Nadal-Roig, E., González-Araya, M.C., \& Pla-Aragones, L.M. (2016). Operational research models applied to the fresh fruit supply chain. European Journal of Operational Research, 251(2), 345-355.

https://doi.org/10.1016/j.ejor.2015.08.046

Soto Silva, W.E., González Araya, M.C., Oliva Fernández, M.A., \& Plà Aragonés, L.M. (2017). Optimizing fresh food logistics for processing: Application for a large Chilean apple supply chain. Computers and Electronics in Agriculture, 136, 42-57. https://doi.org/10.1016/j.compag.2017.02.020

Sun, X., Wu, C.C., \& Chen, L.R. (2018). Cold Chain Logistics Distribution Optimization for Fresh Processing Factory Based on Linear Programming Model. Proceedings of IEEE 3rd Advanced Information Technology, Electronic and Automation Control Conference, LAEAC (593-597). https://doi.org/10.1109/IAEAC.2018.8577759

Trisna, T., Marimin, M., Arkeman, Y., \& Sunarti, T.C. (2016). Multi-objective optimization for supply chain management problem: A literature review. Decision Science Letters, 5(2), 283-316.

https://doi.org/10.5267/j.dsl.2015.10.003

Tsao, Y.C. (2013). Designing a fresh food supply chain network: An application of nonlinear programming. Journal of Applied Mathematics. https://doi.org/10.1155/2013/506531

Utomo, D.S., Onggo, B.S., \& Eldridge, S. (2018). Applications of agent-based modelling and simulation in the agrifood supply chains. European Journal of Operational Research, 269(3), 794-805.

https://doi.org/10.1016/j.ejor.2017.10.041

Van der Vorst, J.G.A.J., Van Kooten, O., \& Luning, P.A. (2011). Towards a diagnostic instrument to identify improvement opportunities for quality controlled logistics in agrifood supply chain networks. International Journal on Food System Dynamics, 2(1), 94-105. http://centmapress.ilb.uni-bonn.de/ojs/index.php/fsd/article/view/119 
van der Vorst, J.G., Schouten, R.E., Luning, P.A., \& van Kooten, O. (2014). Designing new supply chain networks: tomato and mango case studies. Horticulture: Plants for People and Places (1, 1-599). Springer. https://doi.org/10.1007/978-94-017-8578-5

Wang, Y., Shi, Q., Hu, Q., You, Z., Bai, Y., \& Guo, C. (2020). An efficiency sorting multi-objective optimization framework for sustainable supply network optimization and decision making. Journal of Cleaner Production, 272, 122842. https://doi.org/10.1016/j.jclepro.2020.122842

WFPC LLC (2014). The World Food Preservation Center LLC. http://worldfoodpreservationcenter.com/research.html

Yakavenka, V., Mallidis, I., Vlachos, D., Iakovou, E., \& Eleni, Z. (2019). Development of a multi-objective model for the design of sustainable supply chains: the case of perishable food products. Annals of Operations Research, 0123456789. https://doi.org/10.1007/s10479-019-03434-5

Yu, M., \& Nagurney, A. (2013). Competitive food supply chain networks with application to fresh produce. European Journal of Operational Research, 224(2), 273-282. https://doi.org/10.1016/j.ejor.2012.07.033

\section{Appendix: Sets and Parameters, Model}

\begin{tabular}{|c|c|}
\hline \multicolumn{2}{|l|}{ 1. Sets } \\
\hline $\mathrm{I}=$ Areas of agricultural production, index $i$ & (8) \\
\hline $\mathrm{J}=$ Possible location areas of the storage centers index $j$ & (9) \\
\hline $\mathrm{K}=$ Possible location areas of wholesale centers, index $k$ & $(10)$ \\
\hline $\mathrm{F}=$ Types of perishable foods, index $f$ & $(11)$ \\
\hline $\mathrm{P}=$ Market places, index $p$ & $(12)$ \\
\hline $\mathrm{H}=$ Hypermarkets, index $h$ & $(13)$ \\
\hline$C=$ Centers of productive transformation, index $p$ & $(14)$ \\
\hline $\mathrm{DT}=$ set of all possible destinations, index $d, \mathrm{DT}=(J \cup K \cup P U T U H U C)$ & $(15)$ \\
\hline FDT $\{\mathrm{d}\}=$ Set of types of perishable food that can receive the destination $\mathrm{d} \in \mathrm{DT}$ & $(16)$ \\
\hline $\mathrm{DTF}\{\mathrm{f}\}=$ Destination set $\mathrm{d} \in \mathrm{DT}$ that can receive perishable food $f$ & $(17)$ \\
\hline $\mathrm{OT}=$ set of all possible origins, index $0, \mathrm{OT}=(\mathrm{IUJUK})$ & $(18)$ \\
\hline FOT $\{0\}=$ Set of perishable food types that can be sent by the origin or $\in$ OT & $(19)$ \\
\hline DI=set of intermediate and final destinations, index d3, DI=(KUPUTUHUC) & $(20)$ \\
\hline $\mathrm{DNT}_{\mathrm{d} 2}=\sum_{\mathrm{f} \in \mathrm{FDF}\{\mathrm{d} 2\}} \mathrm{DN}_{\mathrm{fd} 2}=$ Total demand on customer $\mathrm{d} 2 \in \mathrm{DF}$ & $(21)$ \\
\hline $\mathrm{FJ}\{j\}=$ Types of perishable goods that can be received in the storage area $j$ & $(22$ \\
\hline $\mathrm{FI}\{\mathrm{i}\}=$ Types of perishable goods found in the area of agricultural production $i$ & (23) \\
\hline \multicolumn{2}{|l|}{ 2. Parameters } \\
\hline $\mathrm{CF}_{\mathrm{j}}=$ Fixed cost of the central storage located in $j$ & $(24)$ \\
\hline $\mathrm{CT}_{\mathrm{od}}=$ Transport cost between the origin or $o \in \mathrm{OT}$ to destination $\mathrm{d} \in \mathrm{DTOT}\{\mathrm{o}\}$ & $(25)$ \\
\hline $\mathrm{CP}_{\mathrm{f}}=$ Cost of loss of perishable food type $f$ & $(26)$ \\
\hline $\mathrm{DN}_{\mathrm{fd} 2}=$ Final destination demand $\mathrm{d} 2 \in \mathrm{DF}$, of the type of perishable good $\mathrm{f} \in \mathrm{FDF}\{\mathrm{d} 2\}$ & $(27$ \\
\hline
\end{tabular}




\begin{tabular}{|c|c|}
\hline $\mathrm{DIN}_{\mathrm{od}}=$ Distance between the origin $o \in \mathrm{OT}$ to destiny $\mathrm{d} \in \mathrm{DTOT}\{\mathrm{o}\}$ & (28) \\
\hline $\mathrm{TN}_{\text {od }}=$ Loss percentage due to temperature change between the origin $o \in \mathrm{OT}$ to destiny $\mathrm{d} \in \mathrm{DTOT}\{\mathrm{o}\}$ & (29) \\
\hline $\mathrm{Hn}_{\mathrm{od}}=$ Loos percentage due to HR between the origin $o \in \mathrm{OT}$ to destiny $\mathrm{d} \in \mathrm{DTOT}\{\mathrm{o}\}$ & (31) \\
\hline LTD $2 E_{\mathrm{d} 2}=$ definition of attention time estimated & (32) \\
\hline \multicolumn{2}{|l|}{ 3. Decision Variables } \\
\hline \multicolumn{2}{|l|}{ 3.1. Opening variables } \\
\hline$X_{j}=\left\{\begin{array}{ll}1 & \text { If a collection centre is opened in the area } j \\
0 & \text { On the contrary }\end{array}\right\}$ & (33) \\
\hline 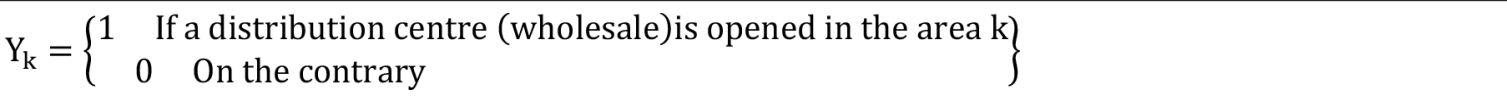 & (34) \\
\hline $\mathrm{BPI}_{\mathrm{i}}=\left\{\begin{array}{cc}1 & \text { if the producer } \mathrm{i} \in \text { is considered } \\
0 & \text { On the contrary }\end{array}\right.$ & (35) \\
\hline \multicolumn{2}{|l|}{ 3.2. Flow variables } \\
\hline $\mathrm{WN}_{\text {fod }}=$ Amount of the type of perishable food $f$ to send from $O$ to $D . \forall$ O $\in \mathrm{OT}, \forall \mathrm{D} \in \mathrm{DT}, \forall \mathrm{f} \in \mathrm{F}$ & (36) \\
\hline \multicolumn{2}{|l|}{ 6.3.3. Excess of offer: } \\
\hline $\mathrm{SFI}_{\mathrm{fo}}=$ Amount of perishable food type $f$ oversupply in echelon $\mathrm{o}, \forall \mathrm{o} \in I, J, K$ & $(37)$ \\
\hline $\begin{array}{l}\text { SFID }_{\mathrm{fd} 2}=\text { Amount of the type of perishable food } f \text { coming from the link } e \text { overbid in the final destination } \mathrm{d} 2, \forall \mathrm{e} \in \\
I, J, K ; \forall \mathrm{d} 2 \in \mathrm{DF} ; \forall \mathrm{f} \in \mathrm{FDF}\{\mathrm{d} 2\}\end{array}$ & (38) \\
\hline
\end{tabular}

Journal of Industrial Engineering and Management, 2021 (www.jiem.org)

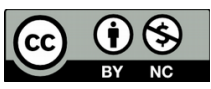

Article's contents are provided on an Attribution-Non Commercial 4.0 Creative commons International License. Readers are allowed to copy, distribute and communicate article's contents, provided the author's and Journal of Industrial Engineering and Management's names are included. It must not be used for commercial purposes. To see the complete license contents, please visit https://creativecommons.org/licenses/by-nc/4.0/. 